\title{
Effect of High Fructose Corn Syrup (HFCS) Intake on the Female Reproductive Organs and Lipid Accumulation in Adult Rats
}

\author{
Eun-Ah Ko, Hye-Ri Kim, Yong-Bin Kim, Hee-Su Kim and 'Sung-Ho Lee \\ Department of Biotechnology, Sangmyung University, Seoul 03016, Korea
}

\begin{abstract}
High-fructose corn syrup (HFCS) is widely used as sweetener, and its overconsumption is become a major health problem. In the present study, we used adult female rats and applied a 28 days HFCS feeding model to monitor the estrous cycle and changes in tissue weights and histology. Adult female rats were divided into three groups. Animals were fed with ad libitum normal chow and (1) 24 hours tap water (Control group), (2) 12 hours HFCS access during dark period and 12 hours tap water (12H group), and (3) 24 hours HFCS only access (24H group). Total exposure period was 28 days. There is no significant change in body weight between control and HFCS-fed animals. Both absolute and relative weights of ovary in $24 \mathrm{H}$ animals were significantly heavier than those in control or $12 \mathrm{H}$ animals. The absolute and relative weights of the kidney and liver in $24 \mathrm{H}$ groups were significantly heavier than those in control or $12 \mathrm{H}$ animals. The estrous cycles of the $24 \mathrm{H}$ animals were significantly longer. Histological analyses revealed that $24 \mathrm{H}$ ovaries were relatively bigger and possessed more corpus lutea than control ovaries. Uterine sections of $12 \mathrm{H}$ and $24 \mathrm{H}$ animals showed a well-developed stratum vasculare between inner and outer myometrial layers. The number of endometrial glands were decreased in $12 \mathrm{H}$ uteri, and recovered in $24 \mathrm{H}$ uteri compared to control. Numbers of convoluted tubule in distal region increased in $12 \mathrm{H}$ and $24 \mathrm{H}$ kidney samples. Liver specimens of $12 \mathrm{H}$ and $24 \mathrm{H}$ showed the increased number of fat containing vacuoles. In conclusion, our study demonstrated that HFCS treatment for 28 days could induce (1) changes in length of estrous cycle with extended estrous and diestrous stages, (2) altered ovarian and uterine histology, and (3) liver and renal lipid accumulation. These findings reveal the adverse effects of HFCS drinking on the reproductive function and lipid metabolism of female rats.
\end{abstract}

Key words : HFCS, Rats, Estrous cycle, Ovary, Uterus, Liver and renal lipid accumulation

\section{INTRODUCTION}

High-fructose corn syrup (HFCS) is a sweetener made from corn starch that has been processed by glucose isomerase to convert glucose into fructose (Ma et al., 2017). HFCS has been widely used as caloric beverages, and is also a primary ingredient in baked goods, cereals, breads, canned fruits, ketchups, jams and jellies, desserts, and fruit juices (Hanover and White, 1993). There is growing appre- hension that the overconsumption of added sugar, including HFCS, is a major health problem, especially for onset of obesity and type 2 diabetes mellitus (T2DM) (Bray et al., 2004; Lakhan \& Kirchgessner, 2013; Toop et al., 2015). Furthermore, several lines of evidence indicate that obesity is associated with multiple adverse reproduc-tive outcomes in female (Broughton \& Moley, 2017).

Meanwhile, recent studies have shown that the high fat diet (HFD) exposure can induce puberty onset and estrous

\footnotetext{
Manuscript received April 21, 2017, Received in revised form April 27, 2017, Accepted May 2, 2017

$\dagger$ Corresponding Author : Sung-Ho Lee, Ph.D., Department of Biotechnology, Sangmyung University, Hongjimoon-2 gil 20, Jongrho-Gu, Seoul 03016, Republic of Korea. Tel: +82-2-2287-5139, Fax: +82-2-2287-0070, E-mail: shlee@smu.ac.kr

This is an Open Access article distributed under the terms of the Creative Commons Attribution Non-Commercial License (http:// creativecommons.org/licenses/by-nc/3.0) which permits unrestricted non-commercial use, distribution, and reproduction in any medium, provided the original work is properly cited.
} 
cycle irregularity in rodent models (Li et al., 2012; Ullah et al., 2017). We also demonstrated that advanced onset of puberty in HFD-fed immature female rats, and this phenomenon is closely related to the activation of KiSS-1 and GnRH expression in the Hypothalamus (Lee et al., 2009). Taken together, these findings strongly support the idea that excessive caloric intake is associated with disturbances of female reproductive function. Since HFCS overconsumption is believed to induce childhood obesity, it could be postulated that HFCS might have similar impact as HFD feeding on the female reproductive system. However, this aspect has not been addressed so far. In the present study, we used adult female rats and applied a 28 days HFCS feeding model to monitor the estrous cycle and changes in tissue weights and histology.

\section{MATERIALS AND METHODS}

\section{Animals}

Sprague-Dawley rats were obtained from DBL (Chungcheongbuk-do, Korea) and reared in our animal facility under conditions of 12-h light/dark cycle (lights on at 07:00 h) and constant temperature of $22 \pm 1^{\circ} \mathrm{C}$. All procedures used were approved by the Animal Care and Use Committee at Sangmyung University in accordance with guidelines established by the Korea Food and Drug Administration (KFDA).

\section{Experimental design}

Age-matched female rats ( 3 months old, 250-275 g, n= 10/ group) were divided into three groups. Animals were fed with ad libitum normal chow (AIN-93G, DBL) and (1) 24 hours tap water (Control group), (2) 12 hours HFCS access during dark period and 12 hours tap water $(12 \mathrm{H}$ group), and (3) 24 hours HFCS only access (24H group). Total feeding period was 28 days. HFCS was purchased commercially available one (CJ Cheiljedang, Formula 55, $\mathrm{v} / \mathrm{v}$ dissolved in tap water, $0.24 \mathrm{Kcal} / \mathrm{ml}$ ), and the working solution was diluted finally to $8 \%$. The stage of the estrous cycle was determined through daily microscopic examination of vaginal smear samples. After 28 days of feeding, the animals were sacrificed by decapitation, and the tissues were collected and weighed.

\section{Histological studies}

Tissues were fixed in 4\% paraformaldehyde overnight at $4{ }^{\circ} \mathrm{C}$ for $24 \mathrm{~h}$. Fixed tissue were dehydrated in ethanol $(70 \%$, $80 \%, 90 \%, 95 \%, 100 \%)$ and embedded in paraffin block. The tissues blocks were cut at 4-5 $\mu \mathrm{m}$ using microtome (HM350S, MICROM, Germany). Sections were stained with hematoxylin-eosin and observed using a light microscope (BX51, Olympus, Japan).

\section{Statistical analyses}

Statistical analysis was performed using Student's $t$-test. Data were expressed as means \pm S.E., and $P$ value $<0.05$ denoted the statistically significant difference.

\section{RESULTS}

\section{Changes in body weights}

Fig. 1 depicts the final body weights of normal chow-fed (CON) and HFCS-fed(12H and 24H) female rats after 28 days feeding. There is no significant change in body weight

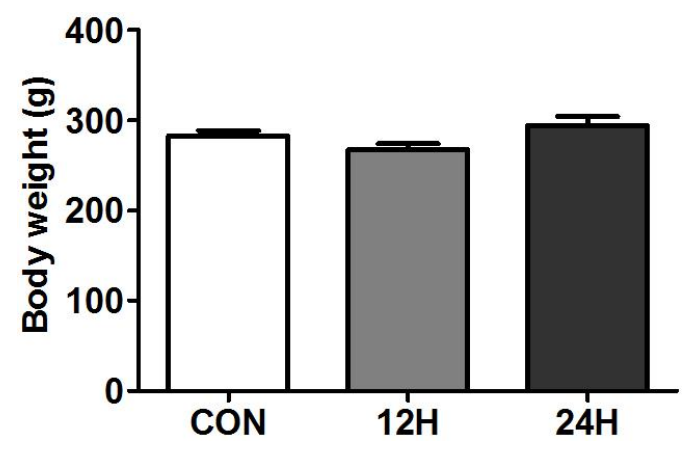

Fig. 1. Final body weights of HFCS treated rats. Adult female rats were treated with HFCS $12 \mathrm{hr}$ per day (12 H, dark period only) or $24 \mathrm{hr}$ per day $(24 \mathrm{H})$ for 28 days. Control animals received tap water (CON). Values are expressed as mean \pm S.E. 
between control and HFCS-fed animals (control vs $12 \mathrm{H}$ vs $24 \mathrm{H}=282.5 \pm 5.0$ vs $267.2 \pm 6.9$ vs $294.2 \pm 9.9$ ).

\section{Changes in the length of estrous cycle}

Daily vaginal smear test showed that the estrous cycles of the whole day HFCS feeding animals $(24 \mathrm{H})$ were significantly longer than control and half day HFCS feeding animals $(12 \mathrm{H})$ (control vs $12 \mathrm{H}$ vs $24 \mathrm{H}=4.7 \pm 0.3$ vs $4.8 \pm$ 0.2 vs 5.6 \pm 0.2 . $P<0.05$; Fig. 2The lengths of estrous and diestrous stages were prolonged in $24 \mathrm{H}$ group animals (data not shown).

\section{Changes in tissue weights}

Table 1 presents the effects of HFCS feeding on changes in tissues weights. Both absolute and relative weights of ovary in $24 \mathrm{H}$ animals were significantly heavier than those in control or $12 \mathrm{H}$ animals (absolute weight : control vs $24 \mathrm{H}=38.0 \pm 2.0$ vs $47.5 \pm 2.8, p<0.05$; relative weights :

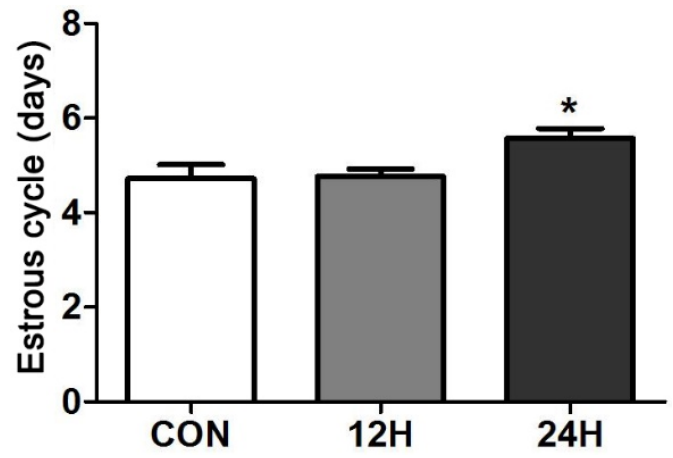

Fig. 2. Changes in the length of estrous cycles in HFCS treated female rats. The vaginal smears were taken daily over the whole testing period of 28 days. Values are expressed as mean \pm S.E. Groups marked with an asterisk $(*)$ are significantly different from control group, $p<0.05$.

Table 1. Comparison of absolute and relative tissue weights of female rats treated with HFCS

\begin{tabular}{ccccc}
\hline \hline & & CON & $12 \mathrm{H}$ & $24 \mathrm{H}$ \\
\hline \multirow{2}{*}{ Ovary } & Absolute(mg) & $38.0 \pm 2.0$ & $39.9 \pm 1.6$ & $47.5 \pm 2.8^{*}$ \\
& Rel & $13.4 \pm 0.6$ & $15.1 \pm 0.8$ & $16.1 \pm 0.8^{*}$ \\
\hline \multirow{2}{*}{ Uterus } & Absolute(mg) & $458.0 \pm 26.0$ & $486.9 \pm 34.1$ & $530.6 \pm 52.8$ \\
& Rel & $162.8 \pm 10.2$ & $184 \pm 15.4$ & $183.4 \pm 21.7$ \\
\hline \multirow{2}{*}{ Kidney } & Absolute(mg) & $794.9 \pm 13.3$ & $809.4 \pm 16.3$ & $898.9 \pm 20.4^{* * *}$ \\
& Rel & $281.8 \pm 5$ & $303.5 \pm 6.0^{*}$ & $306.5 \pm 7.0^{* *}$ \\
\hline \multirow{2}{*}{ Liver } & Absolute(g) & $7.46 \pm 0.13$ & $7.36 \pm 0.37$ & $8.38 \pm 0.33^{*}$ \\
& Rel & $2.64 \pm 0.62$ & $2.75 \pm 0.74$ & $2.85 \pm 0.34^{*}$ \\
\hline \multirow{2}{*}{ Spleen } & Absolute $(\mathrm{mg})$ & $587.4 \pm 23.9$ & $548.4 \pm 32.9$ & $582.7 \pm 26.7$ \\
& Rel & $208.5 \pm 9$ & $207.4 \pm 10.3$ & $199.0 \pm 10.0$ \\
\hline \multirow{2}{*}{ Pancreas } & Absolute(mg) & $657.2 \pm 46.9$ & $620.9 \pm 46.2$ & $695.4 \pm 49.9$ \\
& Rel & $234.3 \pm 19.2$ & $231.5 \pm 15.1$ & $236.1 \pm 14.4$ \\
\hline
\end{tabular}

CON, control group. 12H, 12 hr HFCS accessed animals; 24H, 24 hr HFCS accessed animals; Rel, Relative tissue weights, and is tissue weight (mg) / body weight $(\mathrm{g})$, except liver which is tissue weight ( $\mathrm{g}$ ) / body weight (g).

Values are expressed as mean \pm S.E. Groups marked with an asterisk $\left(^{*}\right)$ are significantly different from control group, $p<0.05\left(^{* *} ; p<0.01,{ }^{* * *} ; p<0.001\right)$. 
$13.4 \pm 0.6$ vs $16.1 \pm 0.8, p<0.05)$. Among the non-reproductive tissues, the absolute and relative weights of the kidney in HFCS-fed groups were signifi-cantly heavier than those in control animals (absolute weights : control vs $24 \mathrm{H}=$ $794.9 \pm 13.3$ vs $898.9 \pm 20.4, p<0.001$; relative weights : control vs $12 \mathrm{H}=281.8 \pm 0.5$ vs $303.5 \pm 0.6, p<0.05$; control vs $24 \mathrm{H}=281.8 \pm 0.5$ vs $306.5 \pm 0.7, p<0.01)$. Likewise, the absolute and relative weights of the liver in HFCS-fed groups were significantly heavier than those in control animals (absolute weights : control vs $24 \mathrm{H}=7.46 \pm 0.13$ vs $8.38 \pm 0.33, p<0.05$; relative weights $: 2.64 \pm 0.62$ vs $2.85 \pm$ $0.34^{*}, p<0.05$ ). In other tissues (uterus, spleen and pancreas), no significant change in the tissue weights was found.

\section{Histological analyses}

Fig. 3 represents the cross sections of the ovary, uterus, kidney and liver tissues used in the present study. The overall size and shape of the $24 \mathrm{H}$ ovaries were relatively bigger than control ovaries. More corpus lutea were found in $24 \mathrm{H}$ ovaries, while secondary follicles were more abun-

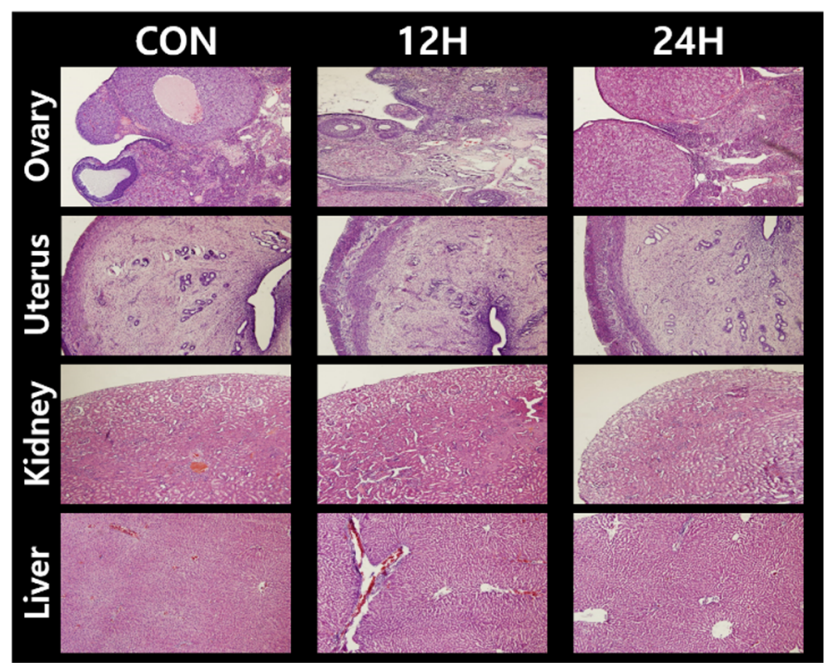

Fig. 3. Histological analyses of the tissues from HFCS treated female rats. After testing period of 28 days, animals were sacrificed and the tissues were immediately collected, then were applied to the standard paraffin section and hematoxylin-eosin staining method. Representative microphotographs $(\times 100)$. dant in control ovaries. The thickened epithelia covering the tissue surface were found in $12 \mathrm{H}$ ovaries. Uterine sections of $12 \mathrm{H}$ and $24 \mathrm{H}$ animals showed a well-developed stratum vasculare between prominent inner and outer myometrial layers. The numbers of endometrial glands were decreased in $12 \mathrm{H}$ uteri, and recovered in $24 \mathrm{H}$ uteri compared to control. Kidney sections revealed that the numbers of convoluted tubule in distal region considerably increased in both $12 \mathrm{H}$ and $24 \mathrm{H}$ samples. Liver specimens of $12 \mathrm{H}$ and $24 \mathrm{H}$ animals showed that the numbers of fat containing vacuoles increased compared to control samples.

\section{DISCUSSION}

Numerous agencies in the United States, such as American Heart Association and the Departments of Agriculture and Health and Human Services, recommend reducing the consumption of all sugars including HFCS. However, there is ongoing debate about the role of HFCS in the spreading obesity epidemic. There is an evidence for a detrimental effect of soft drink consumption on body weight in childhood (Libuda \& Kersting, 2009; Morgan, 2013). Another study also suggests that the increase in consumption of HFCS has a temporal relation to the epidemic of obesity, and the overconsumption of HFCS in calorically sweetened beverages may play a crucial role in the epidemic of obesity (Bray et al., 2004). More specifically, HFCS may contribute to the pathogenesis of nonalcoholic fatty liver disease (NAFLD) which is associated with obesity and insulin resistance (Collison et al., 2009). On the contrary, there is a review study argued that only insufficient evidence are available to ban or restrict use of HFCS in the food supply or to require warning labels on products containing HFCS (Moeller et al., 2009). More recent study also indicates that the available evidence is not sufficiently robust to draw conclusions regarding effects of fructose, HFCS, or sucrose consumption on NAFLD (Chung et al., 2014). In the present study, we found that the HFCS fee- 
ding failed to change the body weight, while HFCS intake induced renal and liver lipid accumulation. The total period of HFCS treatment in our study was for 28 days, which was much shorter than those used in similar studies (Bocarsly et al., 2010; Merino-Aguilar et al., 2014). Treatment for 28 days could be not enough to induce body weight change when compare to over 8 weeks treatments used in above studies. However, our studies on the kidney and liver his-tology assure the adverse effect of HFCS consumption on these tissues. The precise measurements of daily total ca-lorie intake and the ratio of sugar molecules (i.e., fructose, sucrose and glucose) seem to be important factors which can determine the metabolic pathway and the ultimate effect of HFCS consumption.

Concerning the reproductive health, previous study demonstrated that the rats drinking HFCS-55 for 8 weeks showed lengthened estrous cycles due to prolonged estrus (Light et al., 2009). Our result that HFCS access for 4 weeks could induce extended length of estrous cycle is in good agreement with that. Our histological analyses also demonstrated that the changes in ovarian and uterine histology suggest female reproductive function could be altered by HFCS intake. It is well known that female obesity is closely associated with multiple adverse reproductive out-comes in female (Broughton \& Moley, 2017). For example, HFD induced obesity is a trigger of premature puberty onset in immature female rats (Lee et al., 2009), and obesity impairs ovulation but has also been observed to detrimen-tally affect endometrial development and implantation (Brewer \& Balen, 2010). Special attention should be paid to polycystic ovarian syndrome (PCOS) due to its high inci- dence in fertile female population. The expression of PCOS is regulated, in part, by weight, and so obese women with PCOS often have a more severe phenotype and experience more subfertility (Brewer \& Balen, 2010). It will be intri-guing to elucidate whether HFCS overconsumption or high calorie intake from HFCS induces PCOS or aggravates the symptoms.
In conclusion, our study demonstrates that relatively short-term HFCS treatment could induce (1) changes in length of estrous cycle with extended estrous and diestrous stages, (2) altered ovarian and uterine histology, and (3) liver and renal lipid accumulation. As the estrous cycle is lengthened, the rats will become acyclic, a status of reproductive senescence (Westwood, 2008). Despite of the short experimental period, these findings reveal the adverse effects of HFCS drinking on the reproductive function and lipid metabolism of female rats. Further researches in this field will be helpful for understanding the relationship between unhealthy life style (such as overconsumption of HFCS) and obesity, and for maintaining sound reproductive function.

\section{ACKNOWLEDGEMENT}

This work was supported by the National Research Foundation of Korea Grant funded by the Korean Government (NRF-2011-0025490).

\section{REFERENCES}

Bocarsly ME, Powell ES, Avena NM, Hoebel BG (2010) High-fructose corn syrup causes characteristics of obesity in rats: increased body weight, body fat and triglyceride levels. Pharmacol Biochem Behav 97(1): 101106.

Bray GA, Nielsen SJ, Popkin BM (2004) Consumption of high-fructose corn syrup in beverages may play a role in the epidemic of obesity. Am J Clin Nutr 79(4):537543.

Brewer CJ, Balen AH (2010) The adverse effects of obesity on conception and implantation. Reproduction 140 (3): 347-364.

Broughton DE, Moley KH (2017) Obesity and female infertility: potential mediators of obesity's impact. Fertil Steril 107(4):840-847. 
Chung M, Ma J, Patel K, Berger S, Lau J, Lichtenstein AH (2014) Fructose, high-fructose corn syrup, sucrose, and nonalcoholic fatty liver disease or indexes of liver health: a systematic review and meta-analysis. Am J Clin Nutr 100(3):833-849.

Collison KS, Saleh SM, Bakheet RH, Al-Rabiah RK, Inglis AL, Makhoul NJ, Maqbool ZM, Zaidi MZ, AlJohi MA, Al-Mohanna FA (2009) Diabetes of the liver: the link between nonalcoholic fatty liver disease and HFCS-55. Obesity 17(11):2003-2013.

Hanover LM, White JS (1993) Manufacturing, composition, and applications of fructose. Am J Clin Nutr 58: 724S-732S.

Lakhan SE, Kirchgessner A (2013) The emerging role of dietary fructose in obesity and cognitive decline. Nutr $\mathrm{J}$ 2013 Aug 8;12:114. doi: 10.1186/1475-2891-12-114

Lee SY, Jang YS, Lee YH, Seo H-H, Noh KH, Lee S-H (2009) Advanced onset of puberty in high-fat diet-fed immature female rats : Activation of KiSS-1 and GnRH expression in the hypothalamus. Dev Reprod 13(3): 183-190.

Li XF, Lin YS, Kinsey-Jones JS, O'Byrne KT (2012) Highfat diet increases LH pulse frequency and kisspeptinneurokinin B expression in puberty-advanced female rats. Endocrinology 153(9):4422-4431.

Libuda L, Kersting M (2009) Soft drinks and body weight development in childhood: is there a relationship? Curr Opin Clin Nutr Metab Care 12(6):596-600.

Light HR, Tsanzi E, Gigliotti J, Morgan K, Tou JC (2009) The type of caloric sweetener added to water influences weight gain, fat mass, and reproduction in growing Sprague-Dawley female rats. Exp Biol Med 234(6): 651-661.
Ma X, Lin L, Yue J, Wu CS, Guo CA, Wang R, Yu KJ, Devaraj S, Murano P, Chen Z, Sun Y (2017) Suppression of Ghrelin exacerbates HFCS-Induced adiposity and insulin resistance. Int J Mol Sci 18(6). pii: E1302. doi: 10.3390/ijms18061302.

Merino-Aguilar H, Arrieta-Baez D, Jiménez-Estrada M, Magos-Guerrero G, Hernández-Bautista RJ, SusunagaNotario Adel C, Almanza-Pérez JC, Blancas-Flores G, Román-Ramos R, Alarcón-Aguilar FJ (2014) Effect of fructooligosaccharides fraction from Psacalium decompositum on inflammation and dyslipidemia in rats with fructose-induced obesity. Nutrients 6(2):591-604.

Moeller SM, Fryhofer SA, Osbahr Aj, Robinowitz CB, Council on Science Public Health, American Medical Association (2009). The effects of high fructose syrup. J American College Nutr (6):619-626.

Morgan RE (2013) Does consumption of high-fructose corn syrup beverages cause obesity in children? Pediatr Obes 8(4):249-254.

Toop CR, Muhlhausler BS, O'Dea K, Gentili S (2017) Impact of perinatal exposure to sucrose or high fructose corn syrup (HFCS-55) on adiposity and hepatic lipid composition in rat offspring. J Physiol 2017 Apr 26. doi: 10.1113/JP274066.

Ullah R, Su Y, Shen Y, Li C, Xu X, Zhang J, Huang K, Rauf N, He Y, Cheng J, Qin H, Zhou YD, Fu J (2017) Postnatal feeding with high-fat diet induces obesity and precocious puberty in $\mathrm{C} 57 \mathrm{BL} / 6 \mathrm{~J}$ mouse pups: a novel model of obesity and puberty. Front Med 11(2): 266-276.

Westwood FR (2008) The female rat reproductive cycle: a practical histological guide to staging. Toxicol Pathol 36(3):375-384. 